\title{
ARMAZENAGEM DE ÁGUA E PRODUTIVIDADE DE MELOEIRO IRRIGADO POR GOTEJAMENTO, COM A SUPERFÍCIE DO SOLO COBERTA E DESNUDA ${ }^{(1)}$
}

\author{
Jaedson Cláudio Anunciato Mota ${ }^{(2)}$, Paulo Leonel Libardi ${ }^{(3)}$, \\ Alexsandro dos Santos Brito ${ }^{(2)}$, Raimundo Nonato de Assis Júnior ${ }^{(4)}$ \\ \& Joaquim Amaro Filho ${ }^{(5)}$
}

\begin{abstract}
RESUMO
Em regiões com escassez hídrica, a irrigação por métodos que otimizam a aplicação de água às plantas torna-se necessária à produção agrícola. Dessa maneira, o conhecimento da armazenagem de água na camada de solo explorada pelas raízes de uma cultura agrícola ao longo de seu desenvolvimento é essencial ao manejo dos recursos água e solo. Partindo desse problema, o objetivo desta pesquisa foi avaliar a armazenagem de água em Cambissolo cultivado com meloeiro, irrigado por gotejamento, sem e com cobertura da superfície do solo. O experimento foi conduzido em Baraúna-RN, e a estimativa de armazenagem foi feita para a camada de $0-0,3 \mathrm{~m}$, correspondente à camada explorada pelo sistema radicular efetivo da cultura. O monitoramento diário foi realizado durante todo o ciclo, sendo dividido em quatro fases fenológicas: inicial, vegetativa, de frutificação e de maturação. A cobertura da superfície do solo aumentou a armazenagem de água, especialmente nas fases inicial e vegetativa da cultura, mas não teve influência sobre a produtividade e as características pós-colheita dos frutos.
\end{abstract}

Termos de indexação: conteúdo de água, cobertura do solo, irrigação.

\footnotetext{
(1) Parte da Tese do primeiro autor apresentada à ESALQ/USP para obtenção do título de Doutor em Agronomia - Solos e Nutrição de Plantas. Apoio financeiro do CNPq - Brasil. Recebido em dezembro de 2009 e aprovado em julho de 2010.

(2) Doutorando em Agronomia - Solos e Nutrição de Plantas, Escola Superior de Agricultura "Luiz de Queiroz" - ESALQ/USP. Caixa Postal 9, Av. Pádua Dias 11, CEP 13418-900 Piracicaba (SP). Bolsista CNPq e Capes, respectivamente. E-mail: jcamota@esalq.usp.br; alexsb@esalq.usp.br

(3) Professor do Departamento de Ciências Exatas, ESALQ/USP. Bolsista do CNPq. E-mail: pllibard@esalq.usp.br

(4) Professor do Departamento de Ciências do Solo, Universidade Federal do Ceará - UFCE. E-mail: assisjr@ufc.br

(5) Professor aposentado do Departamento de Ciências Ambientais, Universidade Federal Rural do Semi-Árido. E-mail: jamaro@ufersa.edu.br
} 


\title{
SUMMARY: WATER STORAGE AND MUSKMELON PRODUCTIVITY OF A DRIP-IRRIGATED SOIL WITH AND WITHOUT SOIL COVER
}

\begin{abstract}
In regions with water stress, irrigation methods that optimize water application to crops are required for agricultural production. Knowledge on soil water storage in the soil rooting zone during an agricultural crop cycle is essential for water and soil management. The objective of this study was to evaluate water storage in an Inceptisol under drip-irrigated muskmelon, with and without soil cover. The experiment was carried out in the Apodi Tableland, county of Baraúna, state of Rio Grande do Norte, Brazil (05 $04^{\circ} 48 \mathrm{~S}, 37^{\circ} 37^{\prime} 00 \mathrm{~W}$ ). Water storage was estimated for the 0-0.3 $\mathrm{m}$ soil layer, which is the layer explored by the effective root system of crops. Water storage was monitored daily, in the four phenological stages: initial, rapid growth, fructification and maturation. It was concluded that the soil cover increased water storage, especially in the initial and rapid growth stages of the crop, but did not influence the fruit yield and post-harvest characteristics.
\end{abstract}

Index terms: soil water content, soil cover, irrigation.

\section{INTRODUÇÃO}

A cultura do melão (Cucumis melo L.) é explorada atualmente em 84 países. A irrigação foi uma das técnicas que alavancaram a expansão da cultura. Dessa forma, tornou-se possível administrar a quantidade de água necessária à cultura e, assim, obter excelentes produtividades. No entanto, do ponto de vista de manejo, tem sido observada a necessidade de conhecer melhor como se comporta a água no solo ao longo do cultivo e, assim, monitorar o conteúdo dela na camada de solo explorada pelas raízes. Partindo desse conhecimento, é possível manejar bem os recursos água e solo e, consequentemente, a cultura.

De acordo com Pupin et al. (2007), o Brasil ocupa a $20^{a}$ posição entre os países produtores no mundo, sendo os Estados do Rio Grande do Norte e Ceará os maiores produtores. Esses autores, avaliando dados da FAO nos triênios 1993-1995 e 2003-2005, observaram que o Brasil produziu um volume de melão 80 \% maior no último triênio, em comparação ao anterior, percentagem superior à do crescimento mundial. A produção nacional em 2007, segundo dados da Food and Agriculture Organization - FAO (2009), foi de aproximadamente $495.000 \mathrm{t}$, em uma área de 21.576 ha, correspondendo a uma produtividade média de $22,9 \mathrm{t} \mathrm{ha}^{-1}$.

A exploração do meloeiro no semiárido nordestino tem demandado melhoria das práticas de manejo dos fatores relacionados à produção vegetal, envolvendo aspectos ligados a solo, água e tecnologias de póscolheita dos frutos.

A priori, a armazenagem de água no solo depende principalmente da granulometria, da estrutura do solo e do tipo e teor de matéria orgânica. Em segundo plano, o uso do solo e as práticas de manejo têm influência marcante na retenção e na variação da armazenagem de água no solo. Na camada de solo superficial, a dinâmica da água e a variação da armazenagem no espaço e tempo são muito mais acentuadas, por causa da evaporação e atividade das raízes das plantas (González \& Alves, 2005).

A água é retida no espaço poroso do solo pelos mecanismos de adsorção e capilaridade, e sua armazenagem no solo está relacionada aos processos de precipitação pluvial, irrigação, ascensão capilar, drenagem, deflúvios e evapotranspiração. A armazenagem de água no solo é calculada a partir da determinação gravimétrica do conteúdo de água no solo (Brito et al., 2009), por moderação de nêutrons (Barros \& Hanks, 1993; Cruz et al., 2004), por tensiômetros e curva de retenção (Libardi \& Saad, 1994; Paramasivam et al., 2000) e por TDR (Melo Filho \& Libardi, 2005).

No cenário em que todos os esforços convergem para a economia de água no semiárido, tem-se uma prática bastante comum entre os produtores de melão, que é o cultivo do solo com cobertura, natural ou sintética. Além de evitar perda de água por evaporação, a cobertura também promove a melhoria da qualidade dos frutos, por evitar o contato direto deles com o solo. Na região de Mossoró-RN, grande parte dos estudos com a cultura do melão tem sido direcionada para a avaliação de coberturas sintéticas (Câmara et al., 2007; Medeiros et al., 2007a,b). Independentemente do tipo de cobertura, seja natural ou sintética, esses autores julgam a prática da cobertura do solo de suma importância para a região semiárida, considerando que ela pode diminuir os custos de produção no controle de doenças e de plantas invasoras, além de reduzir a quantidade de água aplicada à cultura.

A cobertura do solo altera a relação solo-águaplanta, diminuindo a taxa de evapotranspiração principalmente nos estádios em que o dossel vegetativo não cobre o solo por completo, reduzindo a frequência de irrigação e, por conseguinte, os custos de operação com o sistema de fornecimento de água (Stone et al., 
2006). Bragagnolo \& Mielnikzuk (1990), utilizando palha de trigo como cobertura do solo, verificaram que houve manutenção do conteúdo volumétrico de água na camada de $0-0,05 \mathrm{~m}$ em cerca de 8 a $10 \%$ acima da encontrada para solo sem cobertura. Pereira et al. (2002), aplicando níveis de cobertura do solo $(0,25$, 50,75 e $100 \%$ em feijoeiro irrigado, constataram que não houve variação na produtividade, mas que a economia de água é bastante significativa quando há pelo menos $50 \%$ da superfície do solo com cobertura.

Desse modo, a pesquisa teve por objetivo avaliar a armazenagem de água em um Cambissolo irrigado por gotejamento, sem e com cobertura da superfície, ao longo do ciclo do meloeiro.

\section{MATERIAL E MÉTODOS}

O experimento foi conduzido na Chapada do Apodi, em Baraúna-RN, na safra 2005/2006, cujas coordenadas geográficas são $5^{\circ} 4^{\prime} 48^{\prime}$ " S e $37^{\circ} 37^{\prime} 0$ ” W, em um Cambissolo Háplico (Mota, 2004), onde está implantado um dos prósperos polos de irrigação do Nordeste brasileiro. Para caracterização física do solo da área experimental (granulometria, densidade de partículas e do solo, curva de retenção de água) foram abertas três trincheiras de $1 \mathrm{~m}^{2}(1 \mathrm{x} 1 \mathrm{~m})$ e $0,4 \mathrm{~m}$ de profundidade (uma em cada terço da área experimental) para coleta de amostras de solo com estruturas deformada e não deformada, nas profundidades de 0,1 , 0,2 e $0,3 \mathrm{~m}$. As amostras com estrutura não deformada foram coletadas em anéis volumétricos, tipo Uhland, com altura de $30 \mathrm{~mm}$ e diâmetro de $57,3 \mathrm{~mm}$. As amostras de solo com estrutura deformada foram utilizadas para determinar os pontos das curvas de retenção de água de cada profundidade, em câmaras de Richards, nas tensões de 33, 50, 100, 300, 600, 900, 1.200 e $1.500 \mathrm{kPa}$ (Klute, 1986). Com as amostras não deformadas foram obtidos os pontos, em funil de Haines, nas tensões de 2, 4, 6, 8 e $10 \mathrm{kPa}$ (Klute, 1986).

Em uma área de $20 \times 50$ m, em 10 linhas com extensão de $50 \mathrm{~m}$ cada, cultivou-se melão Amarelo, variedade AF-646, no espaçamento de 2,00 x 0,35 m. Em cada linha foram selecionadas duas plantas, a 1/3 e 2/3 da extensão da linha, ao lado das quais foram instalados três tensiômetros, nas profundidades de 0,$10 ; 0,20$ e $0,30 \mathrm{~m}$, adjacentes à linha de irrigação, distantes $0,10 \mathrm{~m}$ do colo da planta e espaçados de $0,10 \mathrm{~m}$ entre si.

Em cinco das 10 linhas, escolhidas aleatoriamente, fez-se a cobertura com folhas secas de bananeira (Musa sp.) ao longo da linha de gotejamento, numa faixa de $0,5 \mathrm{~m}$. O experimento consistiu de dois tratamentos (sem e com cobertura), com 10 repetições (10 baterias de tensiômetros), em quatro estádios fenológicos: inicial (7-22 DAS - dias após a semeadura), vegetativo (22-40 DAS), frutificação (40-58 DAS) e maturação (58-70 DAS).
Os valores de tensão de água no solo foram obtidos por tensiômetros lidos diariamente, entre 6 e $7 \mathrm{~h}$ da manhã, com suas leituras convertidas em potencial mátrico pela equação:

$$
\phi_{m}=-12,6 h+h_{c}+z
$$

na qual $\phi_{m}$ é o potencial mátrico da água no solo (m água); $h$ é a leitura do tensiômetro $(\mathrm{m} \mathrm{Hg}) ; h_{c}$ é a altura do nível de mercúrio na cubeta em relação à superfície do solo (m água); e $z$ é a distância do centro da cápsula do tensiômetro à superfície do solo (m água). Os valores de $\phi_{m}$ foram convertidos em conteúdo volumétrico de água por meio das equações de ajuste às curvas de retenção da água no solo para a profundidade correspondente.

As eventuais precipitações pluviais foram determinadas com pluviômetro instalado na área experimental e convertidas em precipitação efetiva pela equação (2), proposta pelo USDA Soil Conservation Service (Clarke, 2009) e estudada por Barbosa et al. (2005), para estimativa das necessidades de irrigação na região onde este experimento foi conduzido:

$$
P_{e f}=P(1-0,0016 P)
$$

sendo $P_{e f}$ a precipitação efetiva $(\mathrm{mm})$ e $P$ a precipitação medida com o pluviômetro ( $\mathrm{mm}$ ).

O sistema de irrigação utilizado foi do tipo localizado, por gotejamento, constituído por: um conjunto motobomba, com estação de controle de vazão e pressão; tubulação principal em PVC rígido, com diâmetro nominal de $50 \mathrm{~mm}$; linhas laterais de polietileno flexível de $16 \mathrm{~mm}$ de diâmetro interno; e gotejadores com vazão nominal de $2,0 \mathrm{~L} \mathrm{~h}^{-1}$, com pressão de serviço de $100 \mathrm{kPa}$, e espaçados de $0,35 \mathrm{~m}$ na linha.

Antes do início do experimento, o sistema de irrigação foi avaliado quanto à uniformidade de distribuição de água na área experimental a partir do coeficiente de uniformidade de Christiansen (Zocoler, 1999). Para quantificação desse coeficiente foram coletados dados de vazão de 16 emissores, a saber: quatro da primeiro, quatro da quarta, quatro da sétima e quatro da décima linha lateral de $50 \mathrm{~m}$, de tal maneira que, em cada linha, o primeiro emissor foi o do início da linha $(0 \mathrm{~m})$, o segundo localizava-se a um terço do comprimento da linha, o terceiro a dois terços e o quarto no final da linha $(50 \mathrm{~m})$. Com os dados coletados, calculou-se o coeficiente CUC pela equação 3 :

$$
C U C=1-\frac{\sum_{i=1}^{n}\left|X_{i}-\bar{X}\right|}{n \cdot \bar{X}}
$$

em que $C U C$ é o coeficiente de uniformidade de Christiansen, em decimal; $X_{i}$ é a quantidade de água coletada $\left(\mathrm{L} \mathrm{h}^{-1}\right)$ no i-ésimo emissor; $\bar{X}$ é média das quantidades de água coletadas nos emissores $\left(\mathrm{L} \mathrm{h}^{-1}\right)$; e $n$ é o número de emissores. 
A irrigação foi manejada de modo que o potencial mátrico da água no solo não atingisse valores inferiores a $-40 \mathrm{kPa}$. A lâmina de cada irrigação foi calculada dividindo-se o volume de água aplicado via gotejador pela área molhada na superfície do solo, assumindose como modelo um quadrado de lado Ligual a $0,35 \mathrm{~m}$ (considerou-se o espaçamento entre plantas), em cujo centro localiza-se o gotejador. Neste modelo, no centro do camalhão forma-se uma faixa úmida, com largura de $0,35 \mathrm{~m}$ e comprimento igual ao da linha de gotejadores. Assim, a área molhada em cada planta foi de $0,35 \times 0,35 \mathrm{~m}\left(0,1225 \mathrm{~m}^{2}\right)$, cuja fração em relação à área disponível à planta $\left(0,7 \mathrm{~m}^{2}\right)$ é de 0,175 .

A armazenagem de água foi estimada diariamente para uma camada de solo que teve como limites superior e inferior, respectivamente, a superfície do solo e a profundidade de $0,3 \mathrm{~m}$, pela regra do trapézio (Libardi, 2005), segundo a equação:

$$
h_{z}=\left(1,5 \theta_{0,1 m}+\theta_{0,2 m}+0,5 \theta_{0,3 m}\right) 100
$$

na qual $h_{z}$ é a armazenagem de água na camada de 0-0,3 m, em mm; $\theta_{0,1 \mathrm{~m}}, \theta_{0,2 \mathrm{~m}}$ e $\theta_{0,3 \mathrm{~m}}$, os conteúdos de água, $\mathrm{em} \mathrm{m}^{3} \mathrm{~m}^{-3}$, nas profundidades de 0,$1 ; 0,2 \mathrm{e}$ $0,3 \mathrm{~m}$, respectivamente; e 100 , o valor em $\mathrm{mm}$ do incremento de profundidade $=$ distância vertical entre os pontos de medida de $\theta$. A partir da altura de lâmina de água armazenada, calculou-se a variação diária de armazenagem $\left(\Delta \mathrm{h}_{\mathrm{z}}\right)$ pela equação:

$$
\Delta h_{0-0,3 m}=h_{\text {final }}-h_{\text {inicial }}
$$

em que $\Delta h_{0-0,3 m}$ é a variação de armazenagem na camada de 0 a $0,3 \mathrm{~m} ; h_{\text {final }}$ é a armazenagem na camada de 0 a $0,3 \mathrm{~m}$ no dia atual; e $h_{\text {inicial }}$ é a armazenagem na camada de 0 a $0,3 \mathrm{~m}$ do dia anterior.

Ao final do experimento, 70 dias após a semeadura, determinou-se a produtividade do meloeiro pela contagem e pesagem dos frutos de cada parcela, considerando-se como comercializáveis os frutos com padrão de qualidade para os mercados interno e externo. Aqueles que não atenderam aos padrões de qualidade foram considerados como comercializáveis em feiras livres.

Quanto à qualidade pós-colheita dos frutos, cuja amostragem foi realizada aos 63 dias após a semeadura, analisaram-se comprimento, diâmetro, espessura da polpa, textura e teor de sólidos solúveis totais $\left({ }^{\circ} \mathrm{Brix}\right)$, em dois frutos por parcela. $\mathrm{O}{ }^{\circ} \mathrm{Brix}$ foi determinado em refratômetro digital, com gotas de suco obtidas de fatias do fruto. O comprimento, diâmetro e espessura da polpa foram medidos com régua milimetrada. Com relação à textura, o fruto foi dividido longitudinalmente e, em dois pontos de cada face, determinou-se a resistência usando um penetrômetro com pluger de ponta cônica de $8 \mathrm{~mm}$ de diâmetro, sendo os resultados expressos em Newtons $(\mathrm{N})$.

Os dados foram inicialmente analisados pela estatística descritiva. Esse procedimento foi aplicado para verificar a existência de valores periféricos (outliers) que comprometessem o comportamento médio da característica avaliada. Para a armazenagem de água média diária de cada tratamento, foram calculados (a) o erro-padrão da média, $\sigma(\bar{X})$ :

$$
\sigma(\bar{X})=\frac{\sqrt{\frac{\sum_{i=1}^{n}\left(X_{i}-\bar{X}\right)^{2}}{n-1}}}{\sqrt{n}}
$$

em que $\bar{X}$ é a armazenagem média, $X_{i}$ o valor da iésima armazenagem e $n$ o número de repetições; e (b) a diferença relativa, $\delta_{r}$, entre os tratamentos:

$$
\delta_{r}(\%)=\frac{h_{s c}-h_{c c}}{h_{s c}} \cdot 100
$$

sendo $h_{s c}$ e $h_{c c}$ as armazenagens diárias no solo sem e com cobertura, respectivamente.

Foram aplicados o teste de Kolmogorov-Smirnov a $5 \%$, para verificar a normalidade dos dados, e o teste F, para a análise de variância. Para os dados de armazenagem considerou-se o delineamento experimental inteiramente aleatorizado em esquema fatorial 2 x 4 (são as condições da superfície do solo - sem e com cobertura; e quatro são os períodos fenológicos - inicial, vegetativo, frutificação e maturação) com 10 repetições. Para os dados de produtividade e qualidade póscolheita, considerou-se o mesmo delineamento, porém avaliando apenas os tratamentos principais (solo desnudo e coberto). As médias foram comparadas pelo teste de Tukey a $5 \%$, utilizando o programa estatístico SAS (2002).

\section{RESULTADOS E DISCUSSÃO}

As precipitações pluviais ocorreram apenas nos estádios de frutificação e de maturação, com valores de 7,5 e $121,4 \mathrm{~mm}$, respectivamente. Quanto à irrigação, cujo sistema de fornecimento de água apresentou vazão média de $1,85 \mathrm{~L} \mathrm{~h}^{-1}$ e coeficiente de uniformidade de Christiansen (CUC) de 0,89, foram aplicadas lâminas de 148,5, 320,2, 830,9 e 105,7 mm, respectivamente, para os períodos inicial, vegetativo, de frutificação e de maturação. O somatório das chuvas e irrigações foi de 1.534,2 mm (Figura 1).

No tocante à uniformidade da distribuição da água de irrigação, o sistema de irrigação devidamente dimensionado deve apresentar CUC entre 0,80 e -0,90 (Zocoler, 1999; Marouelli et al., 2003), embora Zocoler (1999) considere que valores menores que 0,80 possam ser admitidos, desde que as precipitações pluviais tenham expressão significativa durante o período de cultivo. 


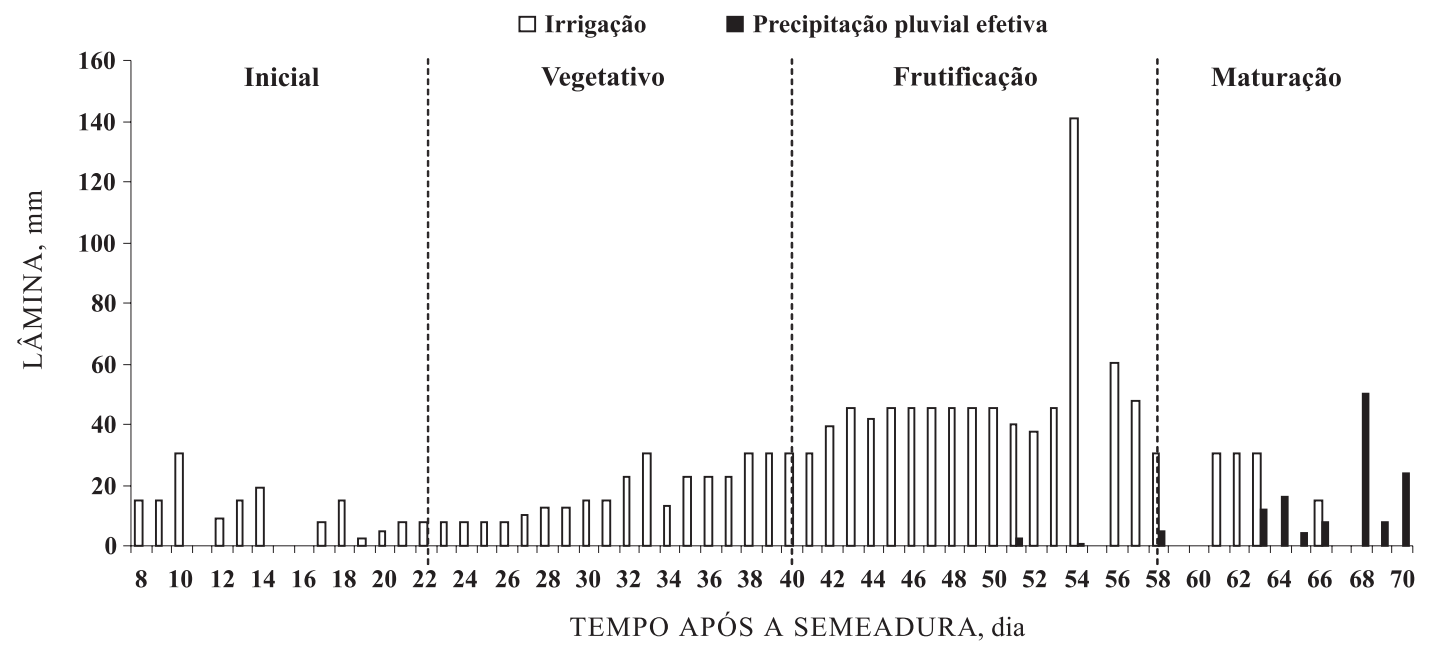

Figura 1. Irrigação e precipitação pluvial efetiva diárias para o balanço de água em Cambissolo Háplico, ocorridas nos quatro estádios fenólogicos.

Os valores apresentados no quadro 1 referem-se ao volume de água por unidade de área molhada e não por unidade de área de terreno explorada pela cultura.

Para comparar o efeito dos tratamentos na armazenagem de água no solo, ao integrar os valores diários no tempo, têm-se duas médias resultantes de mesmas adições e perdas de água, cujas diferenças são devidas única e exclusivamente ao efeito do tratamento, isto é, solo coberto e desnudo.

A análise de variância indicou que há interação significativa entre os tratamentos e períodos fenológicos da cultura (Quadro 2), com os períodos inicial e vegetativo apresentando maior volume de água armazenado na situação de solo coberto. Entre os fatores que interferem na armazenagem de água no solo, a cobertura da superfície contribui para que a perda de água por evaporação seja menor, regulando, em parte, a sua variação no solo.

Considerando a fenologia do meloeiro, nas fases inicial e vegetativa, grande parte da superfície do solo fica exposta, favorecendo perdas de água por evaporação, notadamente na faixa úmida, fato que,
Quadro 2. Armazenagem média de água na camada de $0-0,3 \mathrm{~m}$, em condições de solo sem e com cobertura, nos quatro estádios fenológicos de cultura do meloeiro

\begin{tabular}{llll}
\hline \multirow{2}{*}{ Estádios } & \multicolumn{2}{c}{ Armazenagem (mm) } & \multirow{2}{*}{$\begin{array}{c}\text { Média do } \\
\text { período }\end{array}$} \\
\cline { 2 - 3 } & $\begin{array}{c}\text { Solo sem } \\
\text { cobertura }\end{array}$ & $\begin{array}{c}\text { Solo com } \\
\text { cobertura }\end{array}$ & \\
\hline Inicial & $84,98(0,57) \mathrm{aB}$ & $87,43(0,54) \mathrm{aA}$ & $86,21(0,40) \mathrm{a}$ \\
Vegetativo & $82,09(0,44) \mathrm{abB}$ & $85,73(0,31) \mathrm{aA}$ & $83,91(0,40) \mathrm{b}$ \\
Frutificação & $84,78(0,62) \mathrm{aA}$ & $84,73(0,62) \mathrm{aA}$ & $84,76(0,44) \mathrm{ab}$ \\
Maturação & $80,47(1,25) \mathrm{bA}$ & $80,31(1,21) \mathrm{bA}$ & $80,39(1,11) \mathrm{c}$ \\
Média & $83,08(0,36) \mathrm{B}$ & $84,55(0,35) \mathrm{A}$ &
\end{tabular}

(1) Médias seguidas pela mesma letra, maiúscula na linha e minúscula na coluna, não diferem pelo teste de Tukey a $5 \%$. Valores entre parênteses correspondem ao erro-padrão da média $\left(\mathrm{n}_{\text {inicial }}=160 ; \mathrm{n}_{\text {vegetativo }}=190 ; \mathrm{n}_{\text {frutificação }}=190 ; \mathrm{n}_{\text {maturação }}=\right.$ 130).

em parte, justifica os menores valores de armazenagem de água no solo sem cobertura para esses períodos. Alguns experimentos de campo têm

Quadro 1. Análise estatística descritiva para a armazenagem de água ( $\mathrm{mm}$ ) na camada de 0-0,3 m, nos quatro estádios fenológicos da cultura do meloeiro

\begin{tabular}{|c|c|c|c|c|c|c|c|c|c|}
\hline Estádios & $\mathbf{N}$ & Média & Mediana & Mín. & Máx. & Desv Pad & CV (\%) & Assim. & Curt. \\
\hline \multicolumn{10}{|c|}{ Solo sem cobertura } \\
\hline Inicial & 160 & 85 & 84 & 75 & 111 & 7,24 & 9 & 2,18 & 5,48 \\
\hline Vegetativo & 190 & 83 & 83 & 63 & 110 & 6,01 & 7 & 0,40 & 4,26 \\
\hline Frutificação & 190 & 85 & 85 & 65 & 112 & 8,60 & 10 & 0,60 & 2,49 \\
\hline Maturação & 130 & 80 & 81 & 62 & 108 & 14,21 & 18 & 0,17 & $-1,27$ \\
\hline \multicolumn{10}{|c|}{ Solo com cobertura } \\
\hline Inicial & 160 & 87 & 87 & 77 & 111 & 6,77 & 8 & 2,12 & 5,21 \\
\hline Vegetativo & 190 & 86 & 86 & 74 & 97 & 4,30 & 5 & $-0,34$ & 0,00 \\
\hline Frutificação & 190 & 85 & 85 & 63 & 111 & 8,59 & 10 & 0,56 & 2,54 \\
\hline Maturação & 130 & 80 & 82 & 62 & 109 & 13,84 & 17 & 0,23 & $-1,22$ \\
\hline
\end{tabular}


evidenciado que na fase inicial da cultura o coeficiente de cobertura do solo é bastante pequeno (<3\%) e só atinge $100 \%$ entre 40 e 50 dias após a semeadura, dependendo da variedade cultivada (Dutra et al., 2000; Bezerra et al., 2004). Abu-Awwad (1998) também verificou que em solo sem cobertura havia menos água disponível quando comparado a uma condição de solo coberto, fato que atribuiu às maiores perdas de água por evaporação nos primeiros dias após a irrigação.

Quanto às fases de frutificação e maturação, não foram detectadas diferenças significativas, pelo fato de o solo, em ambos os tratamentos, encontrar-se completamente coberto pela folhagem do meloeiro. Assim, a cobertura aplicada como tratamento perdeu a função de reduzir as perdas de água por evaporação, funcionando apenas como fonte adicional de material orgânico ao solo.

Na armazenagem de água por estádio, observouse que em solo sob cobertura os valores não diferem para os estádios inicial, vegetativo e de frutificação, mas foram superiores aos do último estádio do ciclo do meloeiro. A menor armazenagem para o último período foi devida, em parte, à suspensão do fornecimento de água via irrigação - prática necessária na pré-colheita, que visa melhorar a qualidade dos frutos, principalmente a concentração dos sólidos solúveis totais. Para o solo sem cobertura, a armazenagem no estádio inicial não difere da observada para os estádios de frutificação e vegetativo, com esse último não diferindo do período de maturação, que apresentou menor armazenagem. Em média, os estádios com maior armazenagem foram o inicial e o de frutificação, seguidos pelo vegetativo.

O efeito da cobertura do solo também fica bastante evidente na figura 2 , em que se pode verificar, com base nas curvas e nas diferenças relativas, que em todos os dias dos estádios inicial e vegetativo os valores médios da armazenagem são maiores para o solo coberto. A partir do estádio de frutificação, quando o coeficiente de cobertura do solo pela cultura atinge os $100 \%$, as curvas se cruzam em pequenas flutuações no tempo, com o solo coberto apresentando em alguns dias valor médio de armazenagem menor que o do solo sem cobertura e vice-versa.

Para melhor entendimento da dinâmica da armazenagem de água por camada de solo, isto é, de $0-0,10 ; 0,10-0,20$ e $0,20-0,30 \mathrm{~m}$, verificou-se que para o estádio inicial não houve efeito dos tratamentos na armazenagem de água (Quadro 3). No entanto, no estádio inicial o solo com cobertura apresentou maior armazenagem de água na camada de 0-0,30 m, em relação à condição de solo desnudo.

No estádio vegetativo, o efeito dos tratamentos reflete-se na camada de 0,20-0,30 m, com o solo sem cobertura apresentando menor volume de água armazenado, comparativamente à mesma camada de solo com cobertura. Analisando as condições após uma irrigação, as perdas de água por evaporação na superfície são muito elevadas, uma vez que apenas as condições climáticas governam a transferência de água do solo para a atmosfera. Na literatura, essa fase é conhecida como o estádio I da evaporação (Idso et al., 1974; Suleiman \& Ritchie, 2003; Ventura et al., 2006). À medida que a camada superficial vai secando, temse uma espécie de mulching natural, ou seja, cria-se uma resistência ao fluxo de água devido à quebra da capilaridade e, principalmente, à redução da condutividade hidráulica, isto é, embora haja gradiente hidráulico, as propriedades hidráulicas do solo tornam-se limitantes ao processo de evaporação. Continuando o processo de secamento, a evaporação na camada superficial atinge o estádio II (caracterizado por uma condição em que a água no solo não pode ser transmitida na mesma velocidade da demanda

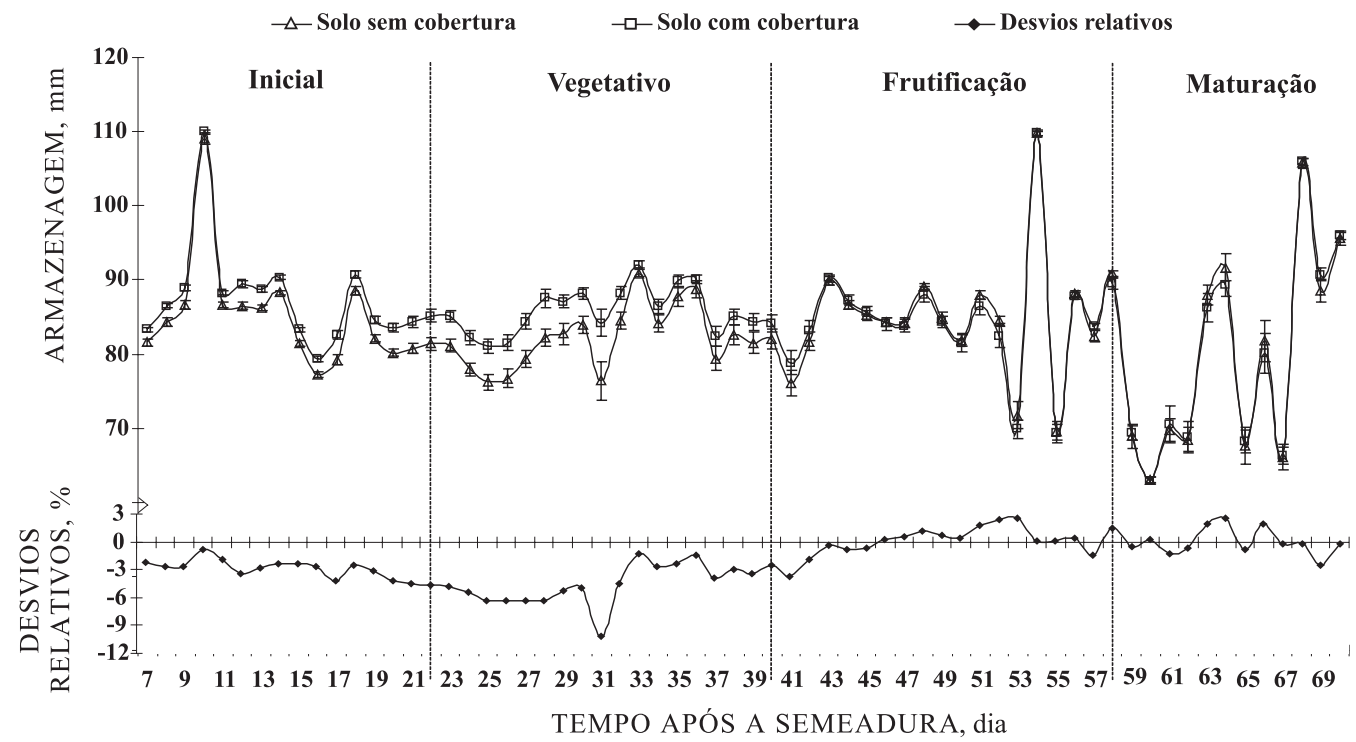

Figura 2. Médias diárias das armazenagens de água e respectivos erros-padrão da média e diferença relativa entre os tratamentos, ao longo do ciclo do meloeiro. 
Quadro 3. Armazenagem média de água nas camadas de 0-0,1; 0,1-0,2 e 0,2-0,3 m, em condições de solo sem e com cobertura, para os quatro estádios fenológicos da cultura do meloeiro

\begin{tabular}{lcll}
\hline \multirow{2}{*}{ Estádios } & $\begin{array}{c}\text { Camada } \\
\text { de solo }\end{array}$ & \begin{tabular}{c} 
Armazenagem (mm) \\
\cline { 3 - 4 } colo sem \\
cobertura
\end{tabular} & $\begin{array}{c}\text { Solo com } \\
\text { cobertura }\end{array}$ \\
\hline Inicial & $\mathrm{m}$ & & \\
& $0,0-0,1$ & $28,20(0,15) \mathrm{aA}$ & $28,87(0,13) \mathrm{aA}^{(1)}$ \\
Média & $0,1-0,2$ & $28,00(0,19) \mathrm{aA}$ & $28,77(0,17) \mathrm{aA}$ \\
Vegetativo & $0,2-0,3$ & $28,78(0,25) \mathrm{aA}$ & $29,79(0,24) \mathrm{aA}$ \\
& & $28,33(0,12) \mathrm{B}$ & $29,14(0,11) \mathrm{A}$ \\
Média & $0,0-0,1$ & $27,97(0,13) \mathrm{aA}$ & $28,75(0,10) \mathrm{aA}$ \\
Frutificação & $27,33(0,13) \mathrm{aA}$ & $28,28(0,10) \mathrm{aA}$ \\
& $0,2-0,3$ & $26,79(0,17) \mathrm{aB}$ & $28,70(0,13) \mathrm{aA}$ \\
& & $27,36(0,09) \mathrm{B}$ & $28,58(0,07) \mathrm{A}$ \\
Média & $0,1-0,1$ & $28,17(0,20) \mathrm{aA}$ & $27,98(0,19)) \mathrm{aA}$ \\
Maturação & $0,2-0,3$ & $28,86(0,21) \mathrm{aA}$ & $27,84(0,20) \mathrm{aA}$ \\
& & $28,26(0,24) \mathrm{aA}$ & $28,92(0,25) \mathrm{aA}$ \\
& $0,0-0,1$ & $27,25(0,42) \mathrm{aA}$ & $28,24(0,13) \mathrm{A}$ \\
Média & $0,1-0,2$ & $26,66(0,42) \mathrm{aA}$ & $26,38(0,40) \mathrm{aA}$ \\
& $0,2-0,3$ & $26,55(0,45) \mathrm{aA}$ & $26,26(0,40) \mathrm{aA}$ \\
& & $26,82(0,25) \mathrm{A}$ & $26,77(0,24) \mathrm{A}$ \\
\hline
\end{tabular}

Médias seguidas pela mesma letra, maiúscula na linha e minúscula na coluna em cada período, não diferem pelo teste de Tukey a $5 \%$. Valores entre parênteses correspondem ao erropadrão da média $\left(\mathrm{n}_{\text {inicial }}=160 ; \mathrm{n}_{\text {vegetativo }}=190 ; \mathrm{n}_{\text {frutificação }}=190\right.$; $\left.\mathrm{n}_{\text {maturação }}=130\right)$.

atmosférica) e, dependendo das circunstâncias, o estádio III (caracterizado por uma evaporação muito baixa, porém constante, controlada por forças de adsorção na interface sólido-líquido no solo; portanto, este estádio é determinado apenas pelas características físicas do solo). Nesses estádios, embora a superfície esteja seca, as camadas mais profundas ainda armazenam quantidade de água suficiente para que a planta não sofra estresse hídrico até uma próxima irrigação.

Analisando ainda a camada de 0,20-0,30 m para as duas condições de cobertura do solo, é razoável supor que, para suprir as perdas de água por evaporação na superfície do solo desnudo, deva haver fluxo ascendente de água por capilaridade das camadas inferiores, pela diferença de potencial total, fato menos intenso no solo coberto. Como as leituras dos tensiometros foram realizadas no início da manhã, havia tempo suficiente, desde o cair da tarde do dia anterior até o momento da leitura, para que houvesse a redistribuição de água no bulbo de molhamento e, assim, a camada superficial voltasse aos estádios iniciais de evaporação. Esse tipo de oscilação diurno-noturna entre os estádios de evaporação foi observado por Idso et al. (1974) e Suleiman \& Ritchie (2003). Portanto, essa redistribuição à noite torna imperceptível a maior evaporação na camada superficial, mas reduz a armazenagem de água para a condição de solo desnudo. Aliado a esse fenômeno, tem-se maior extração de água na camada de 0,20-0,30 m para essa fase fenológica, o que reforça o fato de haver menos água armazenada no solo sem cobertura. Os dois últimos períodos, conforme observado na análise anterior (Quadro 2), são idênticos, uma vez que as condições de cobertura natural do solo serão as mesmas para ambos os sistemas de manejo.

Quanto à armazenagem por camada dentro de cada tratamento, constatou-se que não houve diferença significativa, evidenciando um conteúdo de água no solo semelhante desde a superfície até a camada explorada pelo sistema radicular efetivo do meloeiro.

A variação da armazenagem de água diária é mostrada na figura 3. Constatou-se que o comportamento é muito semelhante em ambos os sistemas de manejo

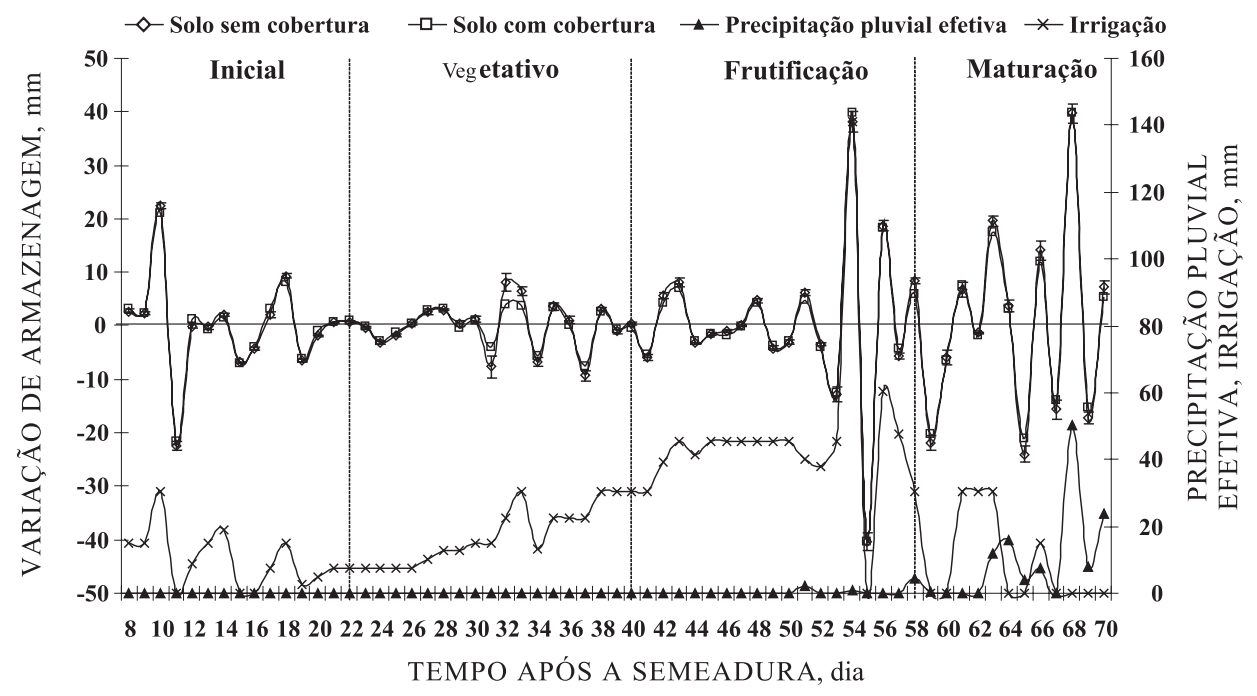

Figura 3. Médias diárias da variação de armazenagem de água nos quatro estádios fenológicos da cultura do meloeiro, com seus respectivos erros-padrão. 
e que, em geral, essa variação reflete o manejo da água aplicada via irrigação e, particularmente, as precipitações pluviais, corroborando resultados de Antonino et al. (2000) e Lima et al. (2006).

Os resultados para cada estádio fenológico estão no quadro 4. Com base no critério de Warrick \& Nielsen (1980) para classificar o coeficiente de variação (baixo - CV $<12 \%$, médio - $12 \%<\mathrm{CV}<60 \%$, alto $\mathrm{CV} \geq 60 \%$ ), constatou-se que os dados apresentaram de média a alta variabilidade.

Valores elevados de coeficiente de variação são comumente citados na literatura que aborda o estudo dos componentes do balanço de água no solo (Reichardt et al., 1993; Villagra et al., 1995; Silva et al., 2006) e refletem a variabilidade espacial natural que os solos apresentam. Villagra et al. (1995) ressaltam que em períodos em que os valores de armazenagem inicial e final são semelhantes, a variação de armazenagem se aproxima de zero, e altos valores de coeficiente de variação podem ser observados. Como havia 10 repetições neste experimento e a irrigação foi manejada para manter o solo aproximadamente com o mesmo conteúdo de água, pequenas variações de armazenagem podem causar altos coeficientes de variação. Entretanto, segundo Reichardt et al. (1993) e Villagra et al. (1995), embora a incerteza da determinação da variação de armazenagem possa ser alta, os valores absolutos são pequenos e não alteram significativamente o cálculo do balanço de água no solo.

Petillo \& Castel (2007) ressaltam que, além da variabilidade espacial de determinados atributos do solo, há um fator limitante, que é a variação do conteúdo de água no solo, especialmente em solo irrigado por gotejamento, no qual a tridimensionalidade da parte molhada é um problema adicional. Nesse caso, esses autores salientam que a variação do conteúdo de água no solo (e consequentemente a variação da armazenagem de água entre estádios fenológicos) é normalmente maior sob sistema de irrigação por gotejamento, por causa da não uniformidade de distribuição da água tanto em superfície quanto em profundidade.

É provável que a irrigação neste experimento tenha contribuído para o aumento da variabilidade dos dados referentes à variação da armazenagem de água no solo, uma vez que a lâmina aplicada pode não ser a mesma em todos os pontos do solo. Ademais, além da variabilidade de características hidráulicas do solo, da não uniformidade da irrigação e das diferenças nas perdas de água por evaporação em diferentes pontos, tem-se a planta como uma importante fonte de variação, pelo fato de a extração de água pelas raízes também não ser uniforme em toda a área. A prova disso é que a maior variabilidade ocorreu no estádio vegetativo, período de estabelecimento e formação da cultura, em que se presume haver elevada atividade da planta na extração de água do solo.

Analisando individualmente a armazenagem de água, fica evidente a necessidade da manutenção do solo coberto para as condições de cultivos irrigados, evitando perdas razoáveis de água para a atmosfera, principalmente nas fases iniciais, quando a parte aérea das plantas ainda não cobre a superfície do solo. $\mathrm{O}$ fato de o solo ser mantido sempre próximo à capacidade de campo quando se utiliza sistema de irrigação de alta frequência favorece, segundo Idso et al. (1974), elevadas taxas de evaporação potencial, em que a evaporação é controlada apenas pelas condições climáticas reinantes. Como no semiárido há demanda elevadíssima de água pela atmosfera, manter o solo em condição de alta armazenagem é o caminho mais fácil para essa transferência.

Observou-se que todas as características relativas à produtividade do meloeiro não apresentaram diferenças significativas em solo cultivado sem e com cobertura (Quadro 5). Embora muitos autores tenham encontrado efeito positivo da cobertura do solo na produtividade e qualidade dos frutos de meloeiro (lbarra et al., 2001; Câmara et al., 2007; Medeiros et al., 2007a,b), outros têm observado resultados semelhantes em ambos os sistemas de cultivo (Araújo et al., 2003; Miranda et al., 2003).

É importante salientar que a maioria das pesquisas com meloeiro tem avaliado o uso do plástico como cobertura; portanto, são pertinentes algumas considerações a respeito desse material em comparação com o material vegetal. A cobertura com polietileno, por permitir melhor contato com o solo, concorre para a redução das perdas de água por evaporação. Por sua vez, o uso de material vegetal na faixa central dos

Quadro 4. Coeficientes de variação (CV) da variabilidade de armazenagem de água no solo nos quatro estádios fenológicos da cultura do meloeiro

\begin{tabular}{|c|c|c|c|c|c|c|c|c|}
\hline \multirow{2}{*}{$\begin{array}{c}\text { Período } \\
\text { Fenológico }\end{array}$} & \multicolumn{3}{|c|}{ Solo sem cobertura } & \multirow{2}{*}{$\begin{array}{l}\text { Classificação } \\
\text { da } \\
\text { variabilidade }^{(1)}\end{array}$} & \multicolumn{3}{|c|}{ Solo com cobertura } & \multirow{2}{*}{$\begin{array}{c}\text { Classificação } \\
\text { da } \\
\text { variabilidade } \\
\end{array}$} \\
\hline & Máx. & Mín. & Médio & & Máx. & Mín. & Médio & \\
\hline Inicial & 95 & 8 & 40 & Média & 79 & 5 & 31 & Média \\
\hline Vegetativo & 368 & 20 & 103 & Alta & 407 & 22 & 120 & Alta \\
\hline Frutificação & 61 & 12 & 28 & Média & 108 & 9 & 42 & Média \\
\hline Maturação & 96 & 15 & 42 & Média & 79 & 10 & 38 & Média \\
\hline
\end{tabular}

(1) Warrick \& Nielsen (1980). 
Quadro 5. Características produtivas e pós-colheita de frutos de meloeiro cultivado em Cambissolo Háplico sem e com cobertura

\begin{tabular}{|c|c|c|c|}
\hline \multirow{2}{*}{ Variáveis } & \multicolumn{2}{|c|}{ Tratamentos } & \multirow{2}{*}{ CV } \\
\hline & Solo sem cobertura & Solo com cobertura & \\
\hline & & & $\%$ \\
\hline Frutos $\left(\mathrm{n}^{0} \mathrm{ha}^{-1}\right)$ & $22.056 \mathrm{a}^{(1)}$ & $20.471 \mathrm{a}$ & 11,37 \\
\hline Matéria fresca (kg/fruto) & $1,46 \mathrm{a}$ & $1,57 \mathrm{a}$ & 7,62 \\
\hline Produtividade $\left(\mathrm{kg} \mathrm{ha}^{-1}\right)$ & $32.150 \mathrm{a}$ & $32.141 \mathrm{a}$ & 11,24 \\
\hline Produção comercial em caixas $\left(\mathrm{kg} \mathrm{ha}^{-1}\right)$ & $25.720 \mathrm{a}$ & $25.713 \mathrm{a}$ & 11,24 \\
\hline Comprimento $(\mathrm{cm})$ & $17,02 \mathrm{a}$ & $16,77 \mathrm{a}$ & 6,08 \\
\hline Diâmetro $(\mathrm{cm})$ & 15,42 a & $14,92 \mathrm{a}$ & 6,27 \\
\hline Espessura da polpa $(\mathrm{cm})$ & $3,82 \mathrm{a}$ & $3,62 \mathrm{a}$ & 8,29 \\
\hline Textura (N) & $24,39 \mathrm{a}$ & $24,71 \mathrm{a}$ & 10,66 \\
\hline Sólidos Solúveis Totais ( $\left.{ }^{\circ} \mathrm{Brix}\right)$ & $8,63 \mathrm{a}$ & $9,00 \mathrm{a}$ & 13,78 \\
\hline
\end{tabular}

(1) Médias seguidas pela mesma letra, na linha, não diferem pelo teste de Tukey a $5 \%$.

canteiros (folha de bananeira, por exemplo) é vulnerável no sentido de permitir, também, perdas consideráveis de água para a atmosfera pelo processo de evaporação, uma vez que não há contato perfeito desse material com o solo. Por conseguinte, é razoável afirmar que a dinâmica da água em ambos os sistemas de cultivo comportou-se de modo bastante semelhante e, dessa maneira, sem efeito significativo sobre a produtividade e qualidade dos frutos.

Quanto ao número de frutos ha-1, Silva et al. (2003), avaliando o desempenho de cultivares na região de Mossoró-RN, encontraram valor de 22.673 frutos ha ${ }^{-1}$ para o híbrido AF-646. A massa média de frutos atendeu aos padrões do híbrido, visto que, pela descrição da cultivar, deve apresentar valores entre 1,2 e 1,5 kg (Sakata, 2008). Em relação à produção total, Crisóstomo et al. (2003) avaliaram o comportamento de híbridos de melão Amarelo em 16 experimentos e verificaram que a produtividade do AF-646 foi de $32.180 \mathrm{~kg} \mathrm{ha}^{-1}$, semelhante, portanto, à obtida neste experimento. Considerando a relação comprimento/diâmetro, verifica-se que é de 1,1 para ambos os tratamentos, indicando que os frutos são arredondados e atendem aos padrões do híbrido (Sakata, 2008).

No tocante às características pós-colheita, os dados também estão de acordo com a literatura pesquisada, não havendo diferença significativa entre os tratamentos.

\section{CONCLUSÃO}

A cobertura da superfície do solo aumenta a armazenagem de água em Cambissolo Háplico cultivado com meloeiro, especialmente nas fases inicial e vegetativa da cultura, porém não tem influência sobre a produtividade e as características pós-colheita dos frutos.

\section{AGRADECIMENTOS}

À empresa WG Fruticultura Ltda., pelo apoio à realização da pesquisa, bem como ao Conselho Nacional de Desenvolvimento Científico e Tecnológico (CNPq), pelo financiamento.

\section{LITERATURA CITADA}

ABU-AWAAD, A.M. Effect of mulch and irrigation water amounts on soil evaporation and transpiration. J. Agron. Crop Sci., 181:55-59, 1998.

ANTONINO, A.C.D.; SAMPAIO, E.V.S.B.; DALL'OLIO, A. \& SALCEDO, I.H. Balanço hídrico em solo com cultivos de subsistência no semi-árido do Nordeste do Brasil. R. Bras. Eng. Agríc. Amb., 4:29-34, 2000.

ARAÚJO, A.P.; NEGREIROS, M.Z.; LEITÃO, M.M.V.B.R.; PEDROSA, J.F.; BEZERRA NETO, F.; ESPÍNOLA SOBRINHO, J.; FERREIRA, R.L.F. \& NOGUEIRA, I.C.C. Rendimento de melão Amarelo cultivado em diferentes tipos de cobertura do solo e métodos de plantio. Hortic. Bras., 21:123-126, 2003.

BARBOSA, F.C.; TEIXEIRA, A.S. \& GONDIN, R.S. Espacialização da evapotranspiração de referência e precipitação efetiva para estimativa das necessidades de irrigação na região do Baixo Jaguaribe - CE. R. Ci. Agron., 36:24-33, 2005.

BARROS, L.C.G. \& HANKS, R.J. Evapotranspiration and yield of beans as affected by mulch and irrigation. Agron. J., 85:692-697, 1993.

BEZERRA, J.W.T.; AZEVEDO, B.M.; VIANA, T.V.A. \& PORTO FILHO, F.Q. Estimativa do coeficiente de cobertura em uma cultura de melão. Irriga, 9:89-93, 2004.

BRAGAGNOLO, N. \& MIELNICZUK, L. Cobertura do solo por palha de trigo e seu relacionamento com a temperatura e umidade do solo. R. Bras. Ci. Solo, 14:369374, 1990. 
BRITO, A.S.; LIBARDI, P.L. \& GHIBERTO, P.J. Componentes do balanço de água no solo com cana-de-açúcar, com e sem adubação nitrogenada. R. Bras. Ci. Solo, 33:295-303, 2009 .

CÂMARA, M.J.T.; NEGREIROS, M.Z.; MEDEIROS, J.F.; BEZERRA NETO, F. \& BARROS JÚNIOR, A.P. Produção e qualidade de melão amarelo influenciado por coberturas do solo e lâminas de irrigação no período chuvoso. Ci. Rural, 37:58-63, 2007.

CLARKE, D. CropWat for Windows: User guide. Disponível em: <http://tarwi.lamolina.edu.pe/ jg oicochea/Manuales/ CROPWAT4W.pdf>. Acesso em: 20 jun. 2009.

CRISÓSTOMO, J.R.; CARDOSO, J.W.; SANTOS, A.A.; CARDOSO, J.E.; BLEICHER, E.; ROSSETTI, A.G.; LIMA, R.N. \& FREITAS, J.G. Desempenho de híbridos de melão amarelo no Ceará e no Rio Grande do Norte, no período 1999-2001. Fortaleza, Embrapa Agroindústria Tropical, 2003. 9p. (Comunicado Técnico, 85)

CRUZ, A.C.R.; LIBARDI, P.L.; CARVALHO, L.A. \& ROCHA, G.C. Consumo hídrico de citros em Latossolo VermelhoAmarelo. In: MENDONÇA, E.S.; XAVIER, F.A.S.; LIBARDI, P.L.; ASSIS JÚNIOR, R.N. \& OLIVEIRA, T.S., orgs. Solo e água: Aspectos de uso e manejo com ênfase no semi-árido nordestino. Fortaleza, Universidade Federal do Ceará, 2004. p.347-373.

DUTRA, I.; MEDEIROS, J.F.; PORTO FILHO, F.Q. \& COSTA, M.C. Determinação do fator de cobertura do melão cultivado sob diferentes lâminas e salinidades da água de irrigação. R. Bras. Eng. Agríc. Amb., 4:146-151, 2000.

FAO. Disponível em: <http://faostat.fao.org>. Acesso em 06 out. 2009

GONZÁLEZ, A.P. \& ALVES, M.C. Armazenamento de água e densidade do solo sob três condições de superfície, em um Cambissol gleico de Lugo, Espanha. R. Bras. Eng. Agríc. Amb., 9:45-50, 2005.

IBARRA, L.; FLORES, J. \& DÍAZ-PÉREZ, J.C. Growth and yield of muskmelon in response to plastic mulch and row covers. Sci. Hortic., 87:139-145, 2001.

IDSO, S.B.; REGINATO, R.J.; KIMBALL, B.A. \& NAKAYAMA, F.S. The three stages of drying of field soil. Soil Sci. Soc. Am. Proc., 38:831-835, 1974.

KLUTE, A. Water retention: Laboratory methods. In: KLUTE, A., ed. Methods of soil analysis. Madison, American Society of Agronomy, Soil Science Society of America, 1986. p.635-662.

LIBARDI, P.L. \& SAAD, A.M. Balanço hídrico em cultura de feijão irrigada por pivô central em Latossolo Roxo. R. Bras. Ci. Solo, 18:529-532, 1994

LIBARDI, P.L. Dinâmica da água no solo. São Paulo, EDUSP, 2005. 329p.

LIMA, J.R.S.; ANTONINO, A.C.D.; SOARES, W.A.; SOUZA, E.S. \& LIRA, C.A.B.O. Balanço hídrico no solo cultivado com feijão caupi. R. Bras. Ci. Agr., 1:89-95, 2006.
MAROUELLI, W.A.; MEDEIROS, J.F.; SILVA, W.L.C. \& PINTO, J.M. Irrigação. In: SILVA, H.R. \& COSTA, N.D., eds. Melão produção: Aspectos técnicos. Brasília, Embrapa, 2003. p.51-68. (Frutas do Brasil, 33).

MEDEIROS, J.F.; SANTOS, S.C.L.; CÂMARA, M.J.T. \& NEGREIROS, M.Z. Produção de melão Cantaloupe influenciado por coberturas do solo, agrotêxtil e lâminas de irrigação. Hortic. Bras., 25:538-543, 2007a.

MEDEIROS, J.F.; SILVA, M.C.C.; SARMENTO, D.H.A. \& BARROS, A.D. Crescimento do meloeiro cultivado sob diferentes níveis de salinidade, com e sem cobertura do solo. R. Bras. Eng. Agríc. Amb., 11:248-255, 2007b.

MELO FILHO, J.F. \& LIBARDI, P.L. Estabilidade temporal de medidas do teor e do potencial mátrico da água no solo em uma transeção. R. Bras. Ci. Solo, 29:497-506, 2005.

MIRANDA, N.O.; MEDEIROS, J.F.; NASCIMENTO, I.B. \& ALVES, L.P. Produtividade e qualidade de frutos de melão em resposta à cobertura do solo com plástico e ao preparo do solo. Hortic. Bras., 21:490-493, 2003.

MOTA, J.C.A. Caracterização física, química e mineralógica, como suporte para o manejo, dos principais solos explorados com a cultura do melão na Chapada do Apodi. Fortaleza, Universidade Federal do Ceará, 2004. 96p. (Tese de Mestrado)

PARAMAVISAM, S.; ALVA, A.K. \& FARES, A. An evaluation of soil water status using tensiometers in a sandy soil profile under citrus production. Soil Sci., 165:343-353, 2000.

PEREIRA, A.L.; MOREIRA, J.A.A. \& KLAR, A.E. Efeitos de níveis de cobertura do solo sobre o manejo da irrigação do feijoeiro (Phaseolus vulgaris, L.). Irrga, 7:42-52, 2002.

PETILLO, M.G. \& CASTEL, J.R. Water balance and crop coefficient estimation of a citrus orchand in Uruguay. Span. J. Agric. Res., 5:232-243, 2007.

PUPIN, F.; VITTI, A. \& BOTEON, M. Avaliação da competitividade do melão no âmbito internacional. 2007. Disponível em: <http://www.usp.br/siicusp/15Siicusp/ 4584.pdf>. Acesso em: 02 jun. 2008.

REICHARDT, K.; BACCHI, O.O.S.; VILLAGRA, M.M.; TURATTI, A.L. \& PEDROSA, Z.O. Hydraulic variability in space and time in a dark red latosol of the tropics. Geoderma, 60:159-168, 1993

SAKATA. Sakata Seed Sudamerica: AF-646. Disponível em: $<$ ht t $: / /$ sakata.com.br/index.php? acti on $=$ catalogo\&cultura $=4 \&$ produto $=79 \&$ language $=p t>$. Acesso em: 02 set. 2008

SAS Institute Inc. The SAS System. Release 9.1.3. Cary, 2002.

SILVA, A.L.; ROVERATTI, R.; REICHARDT, K.; BACCHI, O.O.S.; TIMM, L.C.; BRUNO, I.P.; OLIVEIRA, J.C.M. \& DOURADO NETO, D. Variability of water balance components in a coffee crop in Brazil. Sci. Agric., 63:105114, 2006

SILVA, P.S.L.; MARIGUELE, K.H. \& SILVA, P.I.B. Produtividade do meloeiro em função de cultivares e épocas de semeadura. R. Bras. Frutic., 25:552-554, 2003. 
STONE, L.F.; SILVEIRA, P.M.; MOREIRA, J.A.A. \& BRAZ, A.J.B.P. Evapotranspiração do feijoeiro irrigado em plantio direto sobre diferentes palhadas de culturas de cobertura. Pesq. Agropec. Bras., 41:577-582, 2006.

SULEIMAN, A.A. \& RITCHIE, J.T. Modeling soil water redistribution during second-stage evaporation. Soil Sci. Soc. Am. J., 67:377-386, 2003.

VENTURA, F.; SNYDER, R.L. \& BALI, K.M. Estimating evaporation from bare soil using soil moisture data. J. Irrig. Drain. Eng., 32:153-158, 2006.
VILLAGRA, M.M.; BACCHI, O.O.S.; TUON, R.L. \& REICHARDT, K. Difficulties of estimating evapotranspiration from the water balance equation. Agric. Forest Meteorol., 72:317-325, 1995.

WARRICK, A.W. \& NIELSEN, D.R. Spatial variability of soil physical properties in the field. In: HILLEL, D., ed. Applications of soil physics. New York, Academic Press, 1980. p.319-344.

ZOCOLER, J.L. Avaliação de desempenho de sistemas de irrigação. 1999. Disponível em: <http://www.agr.feis.unesp.br/ curso5.htm>. Acesso em: 28 abr. 2008. 